\title{
PERSEPSI WISATAWAN TERHADAP OBJEK DAYA TARIK WISATA DI KEBUN RAYA LIWA KABUPATEN LAMPUNG BARAT
}

\author{
Perception Of Tourists To The Tourism Attraction Object In Liwa Botanical Gardens, West \\ Lampung Regency
}

\author{
Meri Wulandari, Gunardi Djoko Winarno, Agus Setiawan dan Arief Darmawan
}

Jurusan Kehutanan Fakultas Pertanian Universitas Lampung

Jl. Prof. Dr. Soemantri Brojonegoro No.1, Bandar Lampung

”Email: meriwulandari008@gmail.com

\begin{abstract}
The perception of tourists attraction was very important to be learnt to provide some information for manager to object tourism attraction. The purpose of this research was to analyzed the perceptions of tourists to the objects tourism attractions, accommodation, infrastructure, facilities and services at the Botanical Garden of Liwa. The method used was a questionnaire. The results of this research showed that Liwa Botanical garden has 5 objects tourism attractions that were Ornamental Garden, Fruit Garden, Araceae Garden, Aren Garden and Photo Spot. Araceae Garden, and Aren Garden had the lowest score based on the tourist perception. The highest tourist perception value is the Photo Spot; while the tourist perception of Araceae Park and Aren Park has the lowest value that is classified as not good because the object has not been opened for tourists. Perception of infrastructure was higher than accommodation, facilities and service. Development need to be carried especially in tourist lodgings, objects tourism attraction, the parking area and promotion to introduce Liwa Botanical Garden to the tourists.
\end{abstract}

Keywords: botanic garden, perception, tourist, tourism, tourism attraction object

\section{ABSTRAK}

Persepsi wisatawan terhadap suatu objek wisata sangat penting karena dapat memberikan informasi bagi pengelola dalam pengembangan objek daya tarik wisata. Penelitian ini bertujuan untuk menganalisis persepsi wisatawan terhadap objek daya tarik wisata, akomodasi, infrastruktur, fasilitas dan pelayanan di Kebun Raya Liwa menggunakan metode kuesioner. Hasil penelitian ini menunjukkan Kebun Raya Liwa memiliki 5 objek daya tarik wisata yaitu Taman Hias, Taman Buah, Taman Araceae, Taman Aren, dan Spot Foto. Nilai persepsi wisatawan tertinggi yaitu spot foto; sedangkan persepsi wisatawan terhadap Taman Araceae, dan Taman Aren memiliki nilai terendah yang tergolong kurang baik karena belum dibukanya objek tersebut untuk wisatawan. Persepsi wisatawan terhadap infrastruktur lebih tinggi dibandingkan dengan akomodasi, fasilitas, dan pelayanan. Pengembangan perlu dilakukan terutama pada penginapan pengunjung, memperluas lahan parkir, objek daya tarik wisata yang lebih banyak dan beragam, untuk memperkenalkan Kebun Raya Liwa kepada masyarakat.

Kata Kunci: kebun raya, persepsi, wisatawan, wisata, obyek daya tarik wisata

\section{PENDAHULUAN}

Persepsi wisatawan terhadap suatu objek wisata sangat penting untuk dipelajari, sehingga dapat memberikan informasi bagi pengelola dalam pengembangan objek dan daya tarik wisata alam. Rangkuti (2009) menjelaskan bahwa persepsi adalah proses seseorang untuk menentukan, mengorganisasi dan membagikan informasi agar menciptakan gambaran dunia yang memiliki arti. Menurut Utama et al. (2013) persepsi wisatawan terhadap kebersihan, keamanan, objek dan daya tarik wisata, yang ada di 
destinasi wisata tersebut harus lebih diperhatikan karena hal ini dapat menunjang kegiatan wisata alam.

Kebun Raya adalah asset yang strategis dalam mengurangi dampak perubahan iklim global pada saat ini (Heywood, 2010). Salah satu destinasi yang sedang dikembangkan untuk kegiatan wisata dan dijadikan objek rekreasi serta koleksi spesies tumbuhan di Lampung adalah Kebun Raya Liwa. Kebun Raya Liwa terletak di Desa Kubu Perahu, Kecamatan Balik Bukit, Kabupaten Lampung Barat. Kebun Raya Liwa memiliki luas 86 ha, dibangun pada tahun 2007 bertemakan Tanaman Hias Indonesia. Kebun Raya Liwa dikelola oleh Dinas Kehutanan sampai dengan tahun 2016. Kemudian pada tanggal 3 Januari 2017 pengelolaannya diserahkan kepada Badan Penelitian dan Pengembangan (Balitbang) Lampung barat dan diresmikan oleh Lembaga IImu Penelitian Indonesia (LIPI) pada Tanggal 15 Desember 2017 (Kebun Raya Liwa, 2017).

Penelitian mengenai persepsi wisatawan terhadap Objek Daya Tarik Wisata (ODTW) wisata di Kebun Raya Liwa belum pernah dilakukan sehingga penelitian ini penting dilakukan sebagai langkah awal dalam pengembangan objek daya tarik wisata di Kebun Raya Liwa. Penelitian ini bertujuan untuk menganalisis persepsi wisatawan terhadap objek dan daya tarik wisata alam, akomodasi, infrastruktur, fasilitas dan pelayanan di Kebun Raya Liwa Hasil penelitian ini dapat dijadikan referensi dalam perencanaan pengembangan di lokasi tersebut.

\section{METODE}

\section{A. Lokasi dan Waktu Penelitian}

Penelitian ini dilakukan pada bulan Juni 2018 di Kebun Raya Liwa Kecamatan Balik Bukit Kabupaten Lampung Barat, Provinsi Lampung. Kebun Raya Liwa mempunyai koordinat geografis $05^{\circ} 02^{\prime} 36.6^{\prime \prime}$ LS- $05^{\circ} 01^{\prime} 45.2^{\prime \prime} \mathrm{LS}$, dan $104^{\circ} 04^{\prime} 00.1^{\prime \prime} \mathrm{BT}-104^{\circ} 04^{\prime} 45.9^{\prime \prime} \mathrm{BT}$. Wilayah tersebut termasuk iklim Tipe $B$, dengan curah hujan tahunan rata-rata 2.500-3.000 $\mathrm{mm}$, bulan basah $7-9$ bulan, kisaran suhu $17-30^{\circ} \mathrm{C}$, kelembaban relatif $50 \%-80 \%$. Topografi di area Kebun Raya Liwa landai sampai berbukit- bukit dengan titik tertinggi 945 mdpl dan titik terendah 830 mdpl. Kelas kelerengan $>40 \%$ (curam) yang terletak dibagian selatanbarat Kebun Raya Liwa di sepanjang aliran sungai Way Sindalapai (Kebun Raya Liwa, 2017). Peta lokasi penelitian dapat dilihat pada Gambar 1.

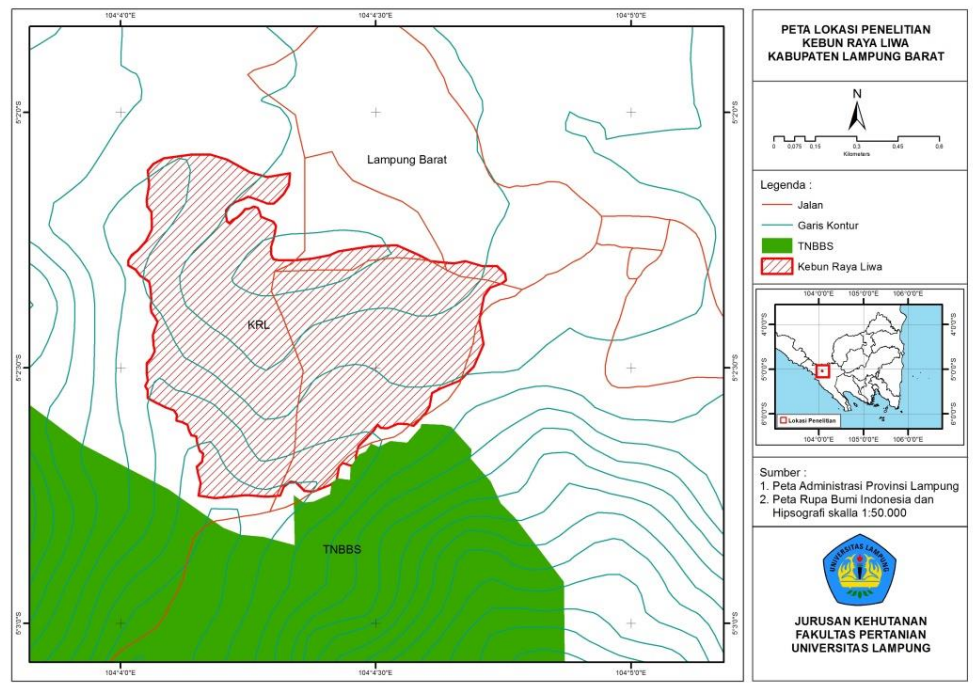

Gambar 1. Peta Lokasi di Kebun Raya Liwa Kecamatan Balik Bukit Kabupaten Lampung Barat

Figure 1. Location Map at the Liwa District Botanical Garden Balik Bukit West Lampung Regency 


\section{B. Pengumpulan Data}

Data yang diambil dalam penelitian ini meliputi data primer dan data skunder. Data primer merupakan data yang diperoleh secara langsung dengan metode wawancara kepada responden menggunakan kuisioner. Data primer berupa persepsi wisatawan dalam pengembangan ODTW, infrastruktur, akomodasi, fasilitas dan pelayanan selanjutnya didokumentasikan menggunakan kamera. Responden adalah wisatawan yang berkunjung di Kebun Raya Liwa. Responden diwawancara sebanyak 50 orang menggunakan metode accidental sampling (Utama et al., 2012). Accidental sampling yaitu cara memperoleh sampel berdasarkan wisatawan yang kebetulan ditemui pada saat melakukan penelitian. Responden dihitung berdasarkan Rumus Slovin (Sugiyono, 2011). Maka jumlah responden pada penelitian adalah:

$$
\begin{aligned}
\text { Rumus: } & \mathrm{n}=\frac{\mathrm{N}}{1+\left(\mathrm{N}\left(\mathrm{e}^{2}\right)\right)} \\
\mathrm{n} \quad & \frac{10000}{1+\left(10000\left(0,15^{2}\right)\right)} \\
= & \frac{10000}{1+225} \\
= & \frac{10000}{226} \\
\mathrm{n} \quad & 50
\end{aligned}
$$

Keterangan:

$$
\begin{array}{ll}
\mathrm{n} & =\text { jumlah sampel } \\
\mathrm{N} & =\text { anggota populasi } \\
\mathrm{e} & =\text { error level }
\end{array}
$$

Data sekunder meliputi informasi berupa peta dan gambaran umum Kebun Raya Liwa yang diperoleh dan dikutip dari studi literature yaitu buku-buku ilmiah, laporan penelitian, jurnal, skripsi, peraturan-peraturan, dan sumber-sumber tertulis lain baik cetak maupun elektronik yang berasal dari kantor Kebun Raya Liwa Lampung Barat.

\section{Analisis Data}

Penilaian skoring pada persepsi oleh responden terdapat lima alternatif jawaban yaitu: sangat tidak baik $=1$, kurang baik $=2$, biasa saja $=3$, baik $=4$, dan sangat baik $=5$. Hasil skoring dianalisis menggunakan tabulasi pengelompokkan data untuk mempermudah proses analisis. Tabulasi diolah menggunakan teknik one score one indicator, yakni satu nilai untuk satu pertanyaan. Hasil total skoring dijumlahkan dan dianalisis dengan Skala Likert untuk menghasilkan grafik persepsi dan alternatif pengembangan Kebun Raya Liwa.

\section{HASIL dan PEMBAHASAN}

\section{A. Karakteristik Responden}

\section{Distrbusi Wisatawan Berdasarkan Jenis Kelamin, Usia dan Tingkat Pendidikan}

Usia responden dibagi dalam beberapa kategori oleh Depkes RI (2009) yaitu remaja, dewasa dan lansia. Distrbusi wisatawan berdasarkan jenis kelamin, usia dan tingkat pendidikan disajikan dalam Tabel 1. Wisatawan laki-laki terutama golongan remaja berusia $<25$ dan tingkat pendidikan perguruan tinggi lebih banyak memberikan penilaian, sedangkan wisatawan perempuan dengan penilaian tertinggi berasal dari golongan remaja berusia $<25$ dan tingkat pendidikan terakhir SLTA. Fenomena tersebut membuktikan usia 17-25 tahun merupakan usia yang masih produktif sehingga berpengaruh terhadap pengambilan 
keputusan berwisata. Karakteristik wisatawan berdasarkan jenis kelamin, usia dan pendidikan terakhir dapat mempengaruhi penilaian. Keliwar dan Nurcahyo (2015) menyatakan tingkat pendidikan berpengaruh terhadap keputusan berwisata karena rasa ingin tahu yang tinggi untuk melihat atau mempelajari keunikan di tempat lain.

Tabel 1. Distribusi wisatawan berdasarkan jenis kelamin, usia dan tingkat pendidikan Table 1. Distribution of tourist gender, age and education level

\begin{tabular}{|c|c|c|c|c|c|c|c|c|c|c|c|c|}
\hline \multirow{3}{*}{ Usia } & \multicolumn{12}{|c|}{ Pendidikan } \\
\hline & \multicolumn{6}{|c|}{ Laki-laki (\%) } & \multicolumn{6}{|c|}{ Perempuan (\%) } \\
\hline & SD & SLTP & SLTA & D3 & PT & Total & SD & SLTP & SLTA & D3 & PT & Total \\
\hline $\begin{array}{c}<25 \\
\text { (Remaja) }\end{array}$ & 2 & 10 & - & 2 & 14 & 28 & - & - & 16 & 2 & 8 & 26 \\
\hline $\begin{array}{c}24-45 \\
\text { (Dewasa) }\end{array}$ & - & 12 & - & 8 & 8 & 28 & - & - & 4 & - & 4 & 8 \\
\hline $\begin{array}{l}>45 \\
\text { (Lansia) }\end{array}$ & - & 2 & - & - & 2 & 4 & - & - & 4 & - & 2 & 6 \\
\hline Jumlah & 2 & 24 & - & 10 & 24 & 60 & - & - & 24 & 2 & 14 & 40 \\
\hline
\end{tabular}

\section{Distribusi Wisatawan Berdasarkan Jenis Kelamin, Pekerjaan dan Pendapatan}

Laki-laki dengan pekerjaan tetap sebagai wiraswasta mempunyai penilaian lebih tinggi yaitu sebanyak 28\% dan pendapatannya sebesar Rp 1.000.000-Rp 5.000.000. Pendapatan wanita yang belum menentu sebagai mahasiswa sebanyak $14 \%$. Hal ini menunjukkan bahwa seseorang yang sudah memiliki pekerjaan dan berpenghasilan tinggi akan lebih besar peluangnya untuk melakukan kegiatan berwisata, karena kegiatan wisata memerlukan biaya. Namun, bukan berarti orang yang memiliki penghasilan yang rendah tidak bisa memutuskan untuk melakukan perjalanan wisata. Distribusi wisatawan berdasarkan jenis kelamin, pekerjaan dan pendapatan dapat dilihat pada Tabel 2 . Keliwar \& Nurcahyo (2015), menyatakan bahwa hubungan antara penghasilan dan pekerjaan dengan kepariwisataan merupakan keterkaitan yang sangat erat.

Tabel 2. Distribusi wisatawan berdasarkan jenis kelamin, pekerjaan dan pendapatan Table 2. Distribution of tourist gender, occupation and income

\begin{tabular}{|c|c|c|c|c|c|c|c|c|}
\hline \multirow[t]{3}{*}{ Pekerjaan } & \multicolumn{8}{|c|}{ Pendapatan } \\
\hline & \multicolumn{4}{|c|}{ Laki - laki (\%) } & \multicolumn{4}{|c|}{ Perempuan (\%) } \\
\hline & $<1.000 .000$ & $\begin{array}{c}1.000 .000 \\
\mathrm{~s} / \mathrm{d} \\
5.000 .000\end{array}$ & $>5.000 .000$ & Total & $<1.000 .000$ & $\begin{array}{c}1.000 .000 \\
\mathrm{~s} / \mathrm{d} \\
5.000 .000\end{array}$ & $>5.000 .000$ & Total \\
\hline PNS & - & - & 2 & 2 & - & 4 & - & 4 \\
\hline Mahasiswa & 20 & - & - & 20 & 14 & 2 & - & 16 \\
\hline Wiraswasta & - & 28 & 4 & 32 & - & 2 & - & 2 \\
\hline Pegawai swasta & - & 8 & - & 8 & - & 4 & - & 4 \\
\hline $\begin{array}{l}\text { Ibu rumah } \\
\text { tangga }\end{array}$ & - & - & - & - & 12 & - & - & 12 \\
\hline Total & 20 & 36 & 6 & 62 & 26 & 12 & - & 38 \\
\hline
\end{tabular}




\section{Distribusi Wisatawan Berdasarkan Daerah Asal Pengunjung}

Penilaian distribusi wisatawan berdasarkan daerah asal dibagi menjadi 3 kategori yaitu Lampung Barat, luar Lampung Barat, dan luar Lampung (Tabel 3). Distribusi pengunjung berdasarkan daerah asal menunjukan bahwa sebagian besar responden yang berkunjung berasal dari daerah Lampung Barat sebanyak 64\%, karena pengunjung yang dekat dengan Kebun Raya Liwa tidak harus mengeluarkan banyak biaya. Berbeda dengan pengunjung yang berasal dari daerah luar Lampung Barat maupun luar Lampung. Mereka harus lebih menyiapkan rencana yang sangat matang untuk memenuhi kebutuhan selama berwisata seperti pengeluaran biaya, waktu luang yang berkaitan dengan pendidikan dan pekerjaan pengunjung.

Tabel 3. Distribusi wisatawan berdasarkan daerah asal pengunjung

Table 3. Distribution of tourist based on visitor's area of origin

\begin{tabular}{lccc}
\hline Daerah asal & Laki-laki (\%) & Perempuan (\%) & Total \\
\hline Lampung Barat & 42 & 22 & 64 \\
Luar Lampung Barat & 18 & 10 & 28 \\
Luar Lampung & 4 & 4 & 8 \\
\hline Total & 64 & 36 & 100 \\
\hline
\end{tabular}

\section{B. Persepsi Wisatawan}

\section{Persepsi Wisatawan terhadap Objek Daya Tarik Wisata}

ODTW yang terdapat di Kebun Raya Liwa yaitu Taman Hias, Taman Buah, Taman Araceae, Taman Aren dan Spot Foto (Tabel 4). Taman Hias, dan Taman Buah sudah dibuka dan bisa dikunjungi wisatawan. Tetapi Taman Araceae dan Taman Aren masih belum dibuka, karena masih ada tanaman yang langka tersimpan di taman tersebut. Objek daya tarik wisata di Kebun Raya Liwa telah diikelompokkan menjadi beberapa taman

Tabel 4. Pengelompokan objek daya tarik wisata di Kebun Raya Liwa

Table 4. Grouping of object attraction in Liwa Botanical Garden

\begin{tabular}{|c|c|c|c|}
\hline No. & $\begin{array}{c}\text { Jenis Tanaman } \\
\text { Tematik }\end{array}$ & Keterangan Tanaman & Foto \\
\hline 1. & Taman Hias & $\begin{array}{l}\text { Tanaman aromatik, tanaman bunga, } \\
\text { tanaman rambat, tanaman mirabilis } \\
\text { dan tanaman araceae }\end{array}$ & \\
\hline 2 & Taman Buah & $\begin{array}{l}\text { Durian, apel, mangga, rambutan binjai, } \\
\text { duku, sirsak, belimbing, jambu biji, } \\
\text { jambu air, jambu bol, alpukat, mangga, } \\
\text { nangka mini, kelengkeng dan sawo. }\end{array}$ & \\
\hline 3. & Taman Araceae & $\begin{array}{l}\text { Taman Araceae terdiri dari } \\
\text { Dipenbachia sp dan Marantha sp }\end{array}$ & \\
\hline
\end{tabular}


4. Taman Aren

5. Spot Foto
Taman Aren dibangun di area perbatasan dengan Taman Nasional Bukit Barisan Selatan dengan luasan 2.6 ha. Tanaman aren yang telah tertanam \pm 1.200 spesimen.

a. Bangku Pelangi

View Taman Nasional Bukit Barisan Selatan. Dengan tempat duduk yang berwarna warni.

b. Tangga Pelangi View spot foto hamparan rumput jepang yang berwarna hijau.

c. Taman Merambat View spot foto tanaman yang merambat di atas besi melingkar seperti gerbang.
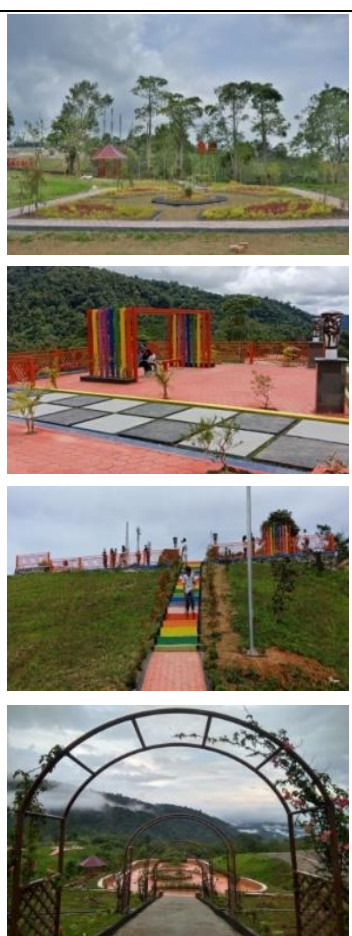

Sumber: Kebun Raya Liwa 2017.

Spot foto merupakan ODTW di Kebun Raya Liwa yang mempunyai nilai tertinggi. Hal ini didukung oleh adanya 3 spot foto seperti: Bangku Pelangi, Tangga Pelangi, dan Taman Merambat dengan latar belakang Taman Nasional Bukit Barisan Selatan. Semua Spot Foto dibuat dari besi dan dicat berwarna-warni. Menurut wisatawan ODTW Taman Aren dan Taman Araceae di Kebun Raya Liwa kurang baik, karena Taman Araceae Maupun Taman Aren saat ini belum dibuka dan lokasinya masih bergabung dengan pusat pembibitan dan terdapat tanaman langka. Nisa \& Arthani (2011), menyatakan bahwa Hutan Pinus dijadikan salah satu ODTW di Kalimantan Selatan. Persepsi wisatawan terhadap ODTW dapat dilihat pada Gambar 2.

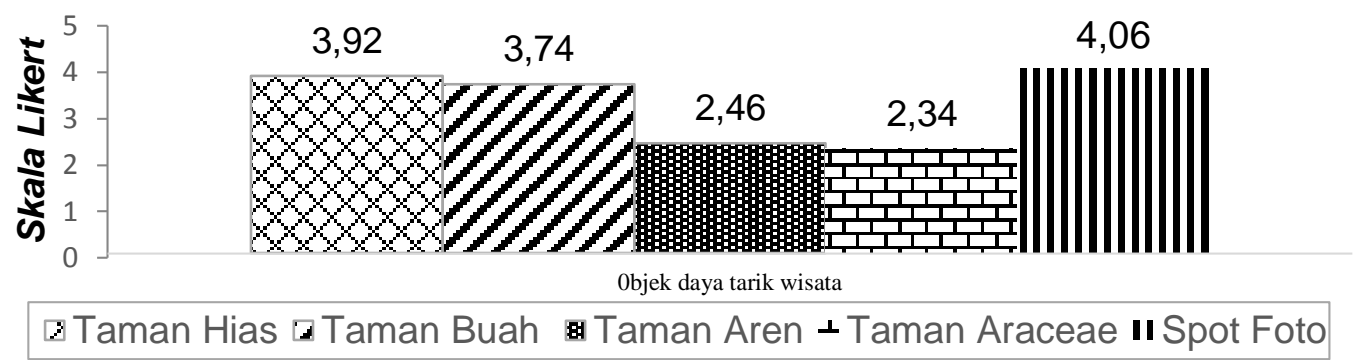

Keterangan penilaian persepsi: 1 = sangat tidak baik, 2 = kurang baik, 3 = cukup baik, 4 = baik, 5 = sangat baik.

Gambar 2. Grafik Persepsi wisatawan terhadap objek daya tarik wisata

Figure 2. Graph of perception of tourists to objects tourists attraction

\section{Persepsi Wisatawan terhadap Akomodasi}

Akomodasi di Kebun Raya Liwa menurut persepsi wisatawa yaitu sangat tidak baik, dengan nilai 1,5 karena mess dan wisma untuk pengunjung dalam tahap perencaanaan pembangunan. Umardiono (2011) menyatakan bahwa fasilitas akomodasi yang masih sangat minim perlu diperhatikan pengembangan baik secara kuantitas maupun kualitasnya untuk meningkatkan kenyamanan dan sebagai penunjang dalam 
pengembangan objek wisata. Persepsi wisatawan terhadap akomodasi dapat dilihat pada Gambar 3.

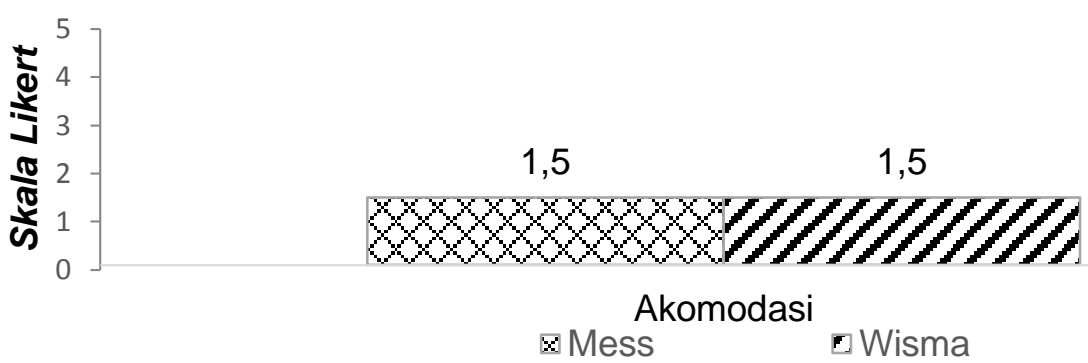

Keterangan penilaian persepsi: $1=$ sangat tidak baik, 2 = kurang baik, $3=$ cukup baik, $4=$ baik, $5=$ sangat baik.

Gambar 4. Persepsi wisatawan terhadap akomodasi

Figure 4. Graph of perception of tourists to accommodation

\section{Persepsi Wisatawan terhadap Infrastruktur}

Infrastruktur di Kebun Raya Liwa yaitu menurut persepsi wisatawan yaitu baik. Hal ini disebabkan pada sepanjang jalan menuju Kebun Raya Liwa sudah di aspal. Tempat parkir di Kebun Raya Liwa masih kurang luas, sehingga perlu adaya penambahan tempat parkir. Menurut Pauwah et al. (2013) bahwa tempat parkir merupakan aspek yang penting untuk diperhatikan karena dapat mempengaruhi kunjungan wisatawan saat membludak. Menurut penelitian Khasani (2014), daya tarik dan fasilitas tidak dapat dicapai dengan mudah kalau belum ada infrastruktur dasar. Pengembangan infrastruktur di suatu daerah tidak hanya dinikmati oleh wisata yang berkunjung saja, tetapi juga dapat dinikmati oleh masyarakat yang tinggal di daerah sekitar wisata tersebut. Penilaian wisatawan terhadap infrastruktur di Kebun Raya Liwa dapat dilihat pada Gambar 3.

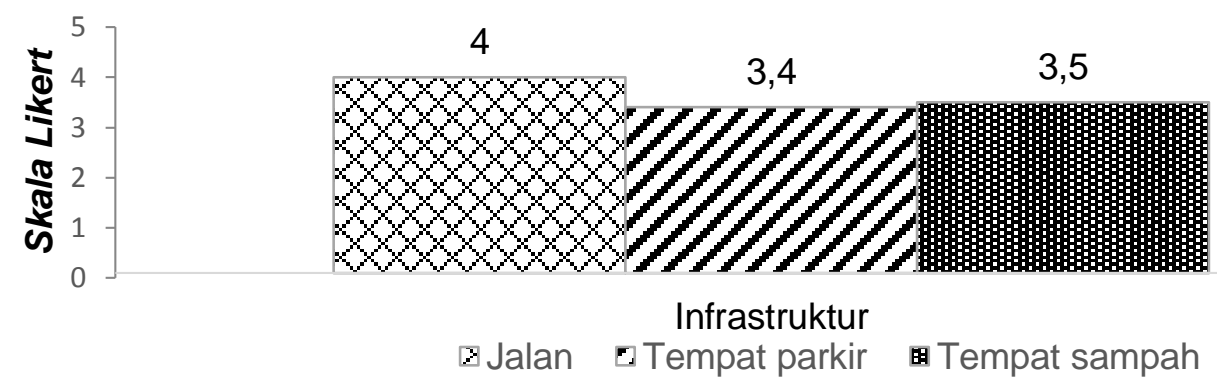

Keterangan penilaian persepsi:

1 = sangat tidak baik, 2 = kurang baik, 3 = cukup baik, 4 = baik, 5 = sangat baik.

Gambar 3. Persepsi wisatawan terhadap infrastruktur di Kebun Raya Liwa Figure 3. Tourist perception of infrastructure in Liwa Botanical Garden

\section{Persepsi Wisatawan terhadap Fasilitas dan Pelayanan}

Persepsi wisatawan terhadap fasilitas dan pelayanan yaitu sangat baik, sehingga harus dijaga dan dirawat agar pengunjung dapat nyaman berwisata dengan fasilitas dan pelayanan yang lengkap. Contohnya adalah mushola di Kebun Raya Liwa yang bersih dan terawat. Namun, wisatawan menilai fasilitas dan pelayanan di Kebun Raya Liwa kurang baik dikarenakan belum adanya cinderamata berbentuk souvenir, untuk dibawa pengunjung. 
Keliwar \& Nurcahyo (2015) menyatakan cinderamata merupakan suatu bentuk sovenir yang dibawa seseorang setelah berkunjung ke suatu tempat dan jenis cinderamata unik menjadi faktor untuk memotivasi wisatawan berkunjung. Menurut Wiradipoetra \& Brahmanto (2018) kerusakan fasilitas akibat kurangnya perawatan dinilai sebagai pemicu persepsi negatif wisatawan terhadap daya tarik wisata, sehingga berdampak pada kurangnya minat untuk berkunjung. Hal ini sejalan dengan pernyataan Wahyulina et al. (2018) bahwa toilet, tempat sampah dan tempat ibadah menjadi sarana paling penting yang diinginkan oleh para wisatawan yang berkunjung. Penilaian wisatawan terhadap fasilitas dan pelayanan di Kebun Raya Liwa dapat dilihat pada Gambar 4.

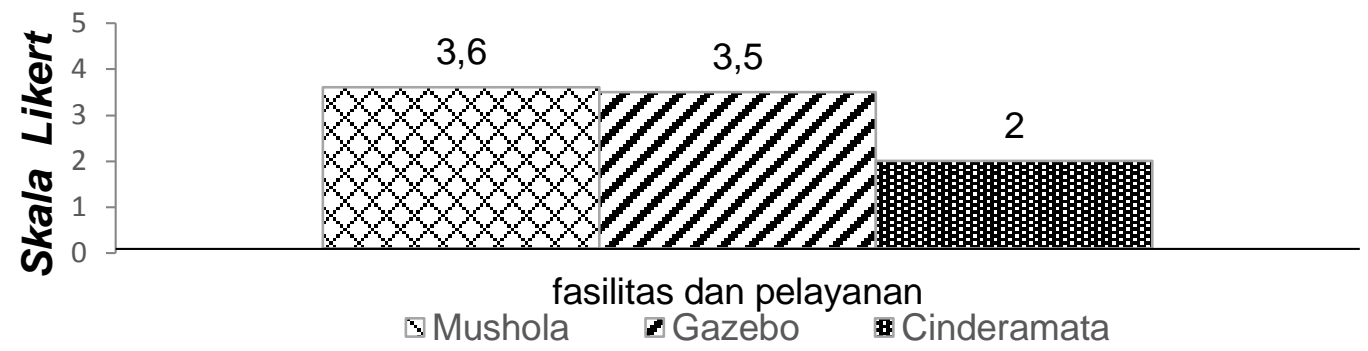

Keterangan penilaian persepsi: $1=$ sangat tidak baik, 2 = kurang baik, $3=$ cukup baik, $4=$ baik, $5=$ sangat baik.

Gambar 4. Persepsi wisatawan terhadap fasilitas dan pelayanan di Kebun Raya Liwa Figure 4. Tourist perception of facilities and services at Liwa Botanical Garden

\section{Perbandingan Nilai Persepsi Wisatawan}

Perbandingan nilai persepsi sangat penting untuk diketahui karena dari perbandingan persepsi wisatawan tersebut dapat membantu pengelola untuk mengembangkan perencanaan pembangunan yang berfokus pada hal apa yang didahulukan, sehingga dapat mendorong peningkatan pengunjung, dari pembenahan berbagai fasilitas layanan, merancang strategi dan program pemasaran yang efektif. Perbandingan nilai persepsi wisatawan terhadap objek dan daya tarik, akomodasi, infrastruktur, fasilitas dan pelayanan dapat dilihat pada Gambar 5. Wibowo (2015) menyatakan bahwa pengelola perlu membenahi layanan yang ada dan melakukan berbagai inovasi layanan untuk menciptakan persepsi positif terhadap kualitas layanan maupun secara keseluruhan.

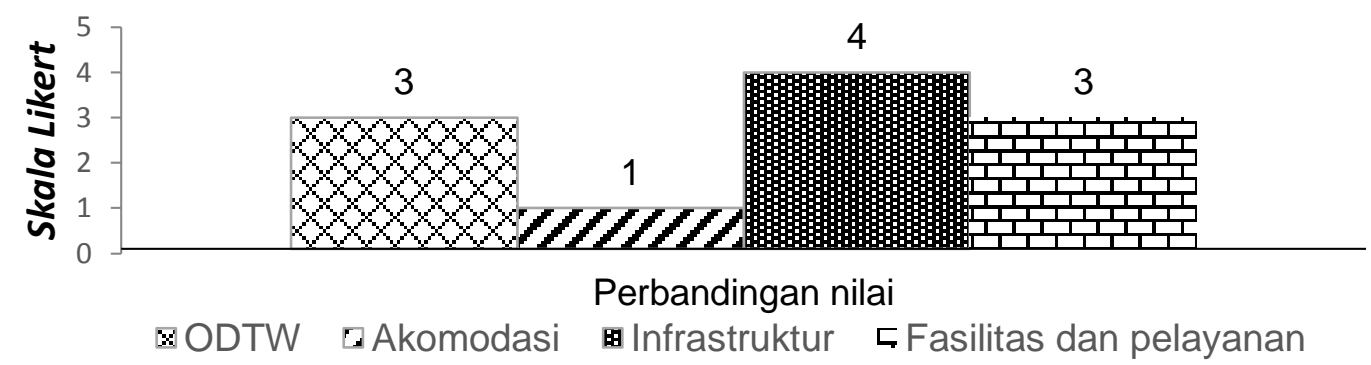

Keterangan penilaian persepsi: 1 = sangat tidak baik, 2 = kurang baik, $3=$ cukup baik, 4 = baik, $5=$ sangat baik.

Gambar 5. Perbandingan nilai perepsi wisatawan terhadap objek daya tarik, akomodasi, infrastruktur, fasilitas dan pelayanan

Figure 5. Comparison of the perceived value of tourists to objects attractiveness, accommodation, infrastructure, facilities and services 
Perbandingan dari semua nilai persepsi wisatawan di atas menunjukkan bahwa penilaian wisatawan terhadap infrastruktur di Kebun Raya Liwa baik. Hal ini terjadi karena infrastruktur selalu dikembangkan untuk menarik wisatawan berkunjung ke Kebun Raya Liwa. Nilai persepsi wisatawan terendah dengan nilai 1 yaitu pada akomodasi, karena menurut pengelola akomodasi untuk wisatawan masih dalam tahap perencanaan pembangunan. Biasanya, wisatawan dari luar kota yang butuh penginapan akhirnya lebih memilih menginap didekat wisata Kebun Raya Liwa. Penilaian terhadap objek dan daya tarik wisata serupa dengan fasilitas dan pelayanan dengan nilai agak baik; artinya, wisatawan masih mengharapkan perlu adanya pembangunan agar wisata di Kebun Raya Liwa bisa lebih lengkap dalam hal objek dan daya tarik wisata, akomodasi, fasilitas maupun pelayanan.

\section{KESIMPULAN dan SARAN}

Kebun Raya Liwa memiliki lima objek daya tarik wisata yaitu Taman Hias, Taman Buah, Taman Araceae, Taman Aren dan Spot Foto. Objek daya tarik wisata yang memiliki skor tertinggi (sangat baik) menurut persepsi wisatawan yaitu Spot Foto karena menarik untuk dikunjungi, sedangkan Taman Araceae dan Taman Aren memiliki score terendah (kurang baik) karena masih belum dibuka untuk wisatawan. Wisatawan menilai bahwa pada Taman Hias dan Taman Buah sudah cukup baik sebagai ODTW. Infrastruktur di Kebun Raya Liwa memiliki skor tertinggi (sangat baik) dibandingkan dengan akomodasi, fasilitas, dan pelayanan. Pengelola perlu melakukan pengembangan terutama pada penginapan pengunjung, ODTW yang lebih banyak dan beragam, serta memperluas lahan parkir. Selain itu, pemasaran perlu ditingkatkan dengan melibatkan pemangku kepentingan seperti pengunjung, agen perjalanan wisata, perguruan tinggi maupun sekolah.

\section{DAFTAR PUSTAKA}

Depkes RI. (2009). Sistem Kesehatan Nasional. Jakarta. Departemen Kesehatan Republik Indonesia

Heywood, H.V. (2010). The Role of Botanic Gardens as Resource and Introduction Centres in The Face of Global Change. Biodiversity Conservation.. https://www.researchgate.net/publication/225131177_The_role_of_botanic_gardens_ as_resource_and_introduction_centres_in_the_face_of_global_change.

Kebun Raya Liwa. (2017). Profil Kebun Raya Liwa. Liwa: Kebun Raya Liwa.

Keliwar, S. \& Nurcahyo A. (2015). Motivation and perception visitor against tourist attractions pampang Cultural Village in Samarinda. Jurnal Manajemen Resort dan Leisure, 12(2), 19-27.

Khasani, M. A. (2014). Analisis Faktor-Faktor yang Mempengaruhi Kunjungan Wisatawan di Pantai Cahaya Weleri Kabupaten Kendal. [Skipsi]. Semarang: Universitas Diponegoro.

Nisa, K. \& Arthani, J. (2011). Kualitas air dan persepsi wisatawan di kawasan wisata alam Pulau Pinus Kalimantan Selatan. Jurnal Hutan Tropis, 12(31), 26-36.

Pauwah, Y., Kumurur, V.A., Sela, R.L.E. \& Rogi, O.H.A. (2013). Persepsi dan preferensi pengunjung terhadap kawasan wisata. Jurnal Unsrat, 5(1), 22-27.

Rangkuti, F. (2009). Strategi Promosi yang Kreatif dan Analisis Kasus Integrated Marketing Communication. Jakarta: PT Gramedia Pustaka Utama.

Sugiyono. 2011. Metode Penelitian Pendidikan Kuantitatif, Kualitatif dan R\&D. Bandung: Alfabeta.

Umardiono, A. (2011). Pengembangan obyek wisata Taman Nasional Laut Kepulauan Karimun Jawa. Jurnal Unair, 24(3), 192-201. 
Jurnal Belantara Vol. 2, No. 2, Agustus 2019 (84-93)

Utama, R., Bagus, I.G. \& Mahadewi, E.N.M. (2012). Metode Pariwisata dan Perhotelan. Yogyakarta: CV Andi Offset.

Wahyulina, S., Darwini, S,. Retnowati, W. \& Oktaryani, S. (2018). Persepsi wisatawan muslim terhadap sarana penunjang wisata halal di Kawasan Desa Sembalun Lawang Lombok Timur. JMM Unram, 7 (1), 27-39.

Wibowo, A.J.I. (2015). Persepsi kualitas layanan museum di Indonesia: Sebuah studi observasi. Jurnal Manajemen, 15(1), 18-40.

Wiradipoetra, F.A. \& Brahmanto, E. (2016). Analisis persepsi wisatawan mengenai penurunan kualitas daya tarik wisata terhadap minat berkunjung. Jurnal Pariwisata, 3(2), 133-137. 